\title{
Increased Serum Calcium Level Promotes the Risk of Lymph Node Metastasis in Endometrial Cancer
}

This article was published in the following Dove Press journal:

Cancer Management and Research

\author{
Xing-Chen $\mathrm{Li}^{1, *}$ \\ Yang-Yang Dong ${ }^{1, *}$ \\ Yuan Cheng' \\ Jing-Yi Zhou ${ }^{1,2}$ \\ Xiao Yang' \\ Bo-Qiang Shen' \\ Xiao-Tong $\mathrm{Wu}^{1,2}$ \\ Xiao-Ping $\mathrm{Li}^{\prime}$ \\ Jian-Liu Wang ${ }^{1,2}$ \\ 'Department of Obstetrics and \\ Gynecology, Peking University People's \\ Hospital, Beijing 100044, People's \\ Republic of China; ${ }^{2}$ Beijing Key \\ Laboratory of Female Pelvic Floor \\ Disorders Diseases, Beijing 100044, \\ People's Republic of China \\ *These authors contributed equally to \\ this work
}

Correspondence: Jian-Liu Wang

Department of Obstetrics and

Gynecology, Peking University People's

Hospital, Beijing 100044, People's

Republic of China

Tel +86 I0 88324474

Email wangjianliul203@I63.com
Purpose: The early predictive values of diagnostic markers for lymph node metastasis (LNM) in endometrial cancer (EC) are still unclear at present. The purpose of this study is to explore the relationship between serum calcium and LNM in EC.

Methods: We identified all patients with EC who underwent surgery between January 2012 and December 2016. Patient characteristics and various preoperative clinicopathologic data were obtained from medical records and were reviewed retrospectively. These patients were divided into two groups according to the pathology of their lymph node. Logistic regression models analyzed the relationship between the ionized calcium and LNM of EC patients, while adjusting for the potential confounders.

Results: A total of 448 patients were assessed. Univariate analysis showed that ionized calcium, CA125 level, tumor grade, peritoneal cytology, FIGO stage, histological type, LVSI, and myometrial invasion were positively correlated with LNM (all $P<0.05$ ). The risk of LNM increased with the promotion of serum ionized calcium $(P$ for trend $<0.01)$. Ionized calcium level was significant before and after the adjustment of cofounders (unadjusted: $\mathrm{OR}=11.9,95 \%$ CI: 4.8-29.6, $P<0.01$; model I: OR=11.3, 95\% CI: 4.5-28.8, $P<0.01$; model II: OR=5.2, 95\% CI: $1.6-17.2, P<0.05)$. Additionally, the risk of ionized calcium was especially evident in patients whose age was older than $60, \mathrm{BMI}<28 \mathrm{~kg} / \mathrm{m}^{2}$, grade 3 , negative peritoneal cytology and endometrioid endometrial adenocarcinoma.

Conclusion: Ionized calcium level was highly associated with LNM in EC and acted as a potential biomarker in predicting the risk of LNM in EC.

Keywords: serum calcium level, EC, lymph node metastasis, stratification analysis

\section{Introduction}

Endometrial cancer (EC) is the most common gynecologic malignancy in developed countries. ${ }^{1}$ The estimated 5-year overall survival for early stage is $80 \%$ to $85 \%$, a number that decreases remarkably to $67 \%$ and $15.9 \%$ for regional and distant metastasis, respectively. ${ }^{2}$ Lymph node metastasis (LNM) is an essential factor for poor prognosis in women with EC. However, there is great controversy regarding whether routine lymphadenectomy is necessary for EC patients, especially those at low-risk. While some studies suggest no survival benefit for routine lymphadenectomy in $\mathrm{EC}^{3}{ }^{3}$ other scholars believe that pelvic lymphadenectomy provides both diagnostic and therapeutic value. Therefore, it is imperative to find biomarkers and preoperative risk factors of LNM and improve preoperative assessment for radical lymphadenectomy in EC.

Currently, several factors and models are used to predict LNM. The Mayo clinic model suggests myometrial invasion, tumor diameter and histological type, ${ }^{4}$ while 
the Korean Gynecologic Oncology Group's (KGOG) modified model uses MRI, CA125, and endometrioid histology. ${ }^{5}$ Other models include lymph-vascular space invasion (LVSI), stromal involvement and estrogen receptor (ER), progesterone receptor (PR) in EC. However, risk factors for LNM resulting from EC are still unclear.

Since tumor markers routinely used in EC cannot accurately predict the risk of LNM, other metastatic indexes for LNM are required. Serum calcium levels, a cheap, objective and easily accessible index in clinical work, have long been found to play an important role in LNM. ${ }^{6}$ Our previous work suggested that calcium and its channel Cav1.3, promoted proliferation and migration in EC cells. ${ }^{7}$ Calcium levels and its channel, TRPV4 had also been found playing an essential role in gastric cancer. ${ }^{8}$ High serum calcium levels have been found to be associated with many malignancies, including breast and renal carcinomas as well as squamous cell carcinomas of any organ. However, almost $50 \%$ of calcium is not physiologically active as it is bound to albumin in blood. Thus, an estimate of the active fraction of serum calcium adjusts the serum calcium for the level of serum albumin.

In this study, we tried to find risk factors for LNM and evaluate the relationship between risk factors and LNM. Furthermore, we examined the correlation between LNM and preoperative activated calcium (ionized calcium) in different stratifications.

\section{Patients and Methods}

\section{Patient Selection}

Data from all patients who were diagnosed with EC and underwent surgery were retrospectively reviewed between January 2012 and December 2016 at Peking University People's Hospital, Beijing, China. The disease was diagnosed by postoperative pathology. Patients who received neoadjuvant therapy or endocrine therapy were excluded, as well as those who were not subjected to lymphadenectomy, and those whose pathology was accompanied by other cancers or recurrent disease. The study protocol was approved by the ethics committee of Peking University People's Hospital (2015PHB116-01). All patients signed written informed consents and this study was conducted in accordance with the Declaration of Helsinki.

\section{Patient Characteristics}

Demographic data including age, body mass index (BMI), menopausal status, diabetes and hypertension were collected from medical records. We obtained clinicopathological data such as preoperative CA125, serum calcium, albumin, number of lymph node (LN) removed, tumor grade $(\mathrm{G})$, peritoneal cytology, FIGO stage, histological type, LVSI, myometrial invasion, and lymphadenectomy. The fasting venous blood was collected one day before surgery and used for the measurement of the concentrations of preoperative serum CA125, calcium, and albumin. Tumor grade and FIGO stage were defined according to FIGO guidelines revised in $2009 .^{9}$ Peritoneal cytology, histological type, LVSI, myometrial invasion, LNM, and number of LN removed were obtained from the pathology reports. The relationship between these clinicopathological factors and LNM was evaluated in EC patients. The biologically active fraction of serum calcium (ionized calcium) was calculated by the following formula: Serum albumin-corrected calcium $(\mathrm{mg} / \mathrm{dL})=$ total serum calcium $(\mathrm{mg} / \mathrm{dL})+0.8 *(4-$ albumin $(\mathrm{g} / \mathrm{dL}))$.

\section{Statistical Analysis}

Data are presented as mean \pm standard deviation (SD) for continuous variables, and as frequency or percentage for categorical variables. The Mann-Whitney and Chi-square tests were used to determine any statistical difference between the means and proportions of the two groups. Both non-adjusted and multivariate adjusted models were applied. We performed tests for linear trend by entering the three categories of ionized calcium level as a continuous variable in the models. Interaction and stratified analyses were conducted according to age, BMI, menopausal status, diabetes, hypertension, preoperative CA-125, total serum calcium, albumin, tumor grade, peritoneal cytology, FIGO stage, histological type, LVSI, myometrial invasion. The interaction between ionized calcium and LNM in different subgroups was examined by likelihood ratio tests. All of the analyses were performed with the statistical software packages R version 3.4.3 (http://www.R-project. org, The R Foundation) and EmpowerStats (http://www. empowerstats.com, X\&Y Solutions, Inc., Boston, MA). A two-sided significance level of 0.05 was considered statistically significant.

\section{Results}

\section{Patients and Clinicopathological Characteristics}

During the study period, 510 patients underwent surgery for EC and a total of 448 women fulfilled the inclusion and exclusion criteria were identified in this research (Figure 1). Basic characteristics of the patients stratified by positive or negative LNM are shown in Table 1. There were 401 patients 


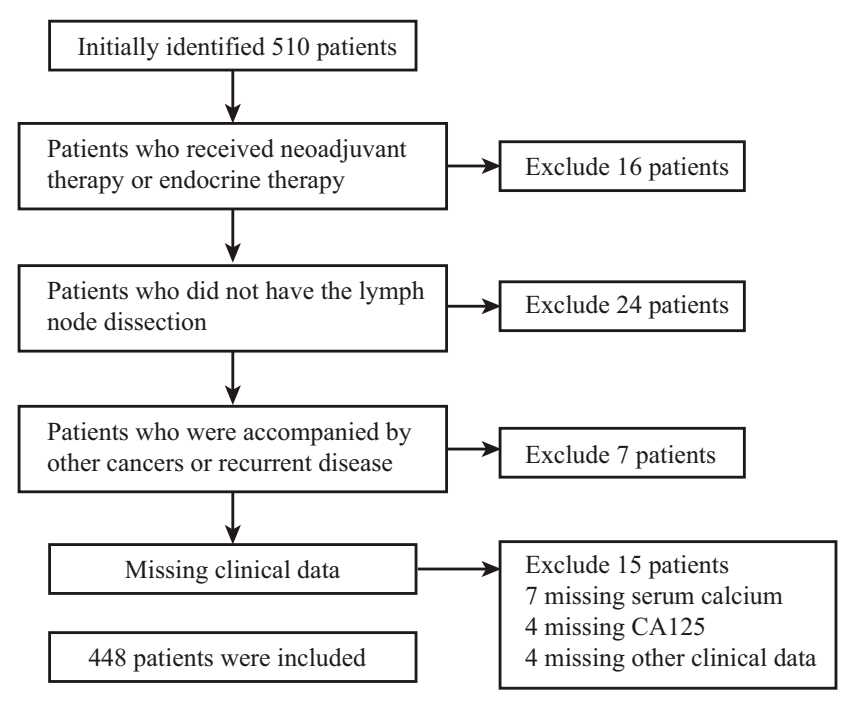

Figure I Flow chart of selection of 448 endometrial cancer patients.

in negative LNM group and 47 patents in positive LNM group. Median age in the two groups was $55.5 \pm 9.5$ and $57.3 \pm 8.5$ years old, respectively. The median value of serum calcium was $2.3 \pm 0.2 \mathrm{mg} / \mathrm{dL}$ and $2.3 \pm 0.3 \mathrm{mg} / \mathrm{dL}$. After adjusting for serum albumin $(4.4 \pm 0.4 \mathrm{mg} / \mathrm{dL}$ and $4.0 \pm$ $0.5 \mathrm{mg} / \mathrm{dL}$ ) using the formula provided above, the calculated median ionized calcium was $2.0 \pm 0.3 \mathrm{mg} / \mathrm{dL}$ and $2.3 \pm$ $0.5 \mathrm{mg} / \mathrm{dL}$. For CA125, the median level was $39.7 \pm 98.5$ $\mathrm{U} / \mathrm{mL}$ and $172.8 \pm 459.5 \mathrm{U} / \mathrm{mL}$ in the two groups. The majority of patients (64.3\% and 57.4\%) were postmenopausal in both groups. In terms of other clinicopathological indexes in the negative LNM group, $323(80.5 \%)$ patients were in grade $1(\mathrm{G} 1)$ and grade $2(\mathrm{G} 2), 25(19.5 \%)$ in grade 3 (G3). $6.2 \%(n=25)$ and $19.1 \%(n=9)$ of the patients had positive peritoneal cytology. Among all patients in the whole cohort, the majority of the patients were in FIGO stage I and EEA in the aspect of histological type. The distribution of patients in LVSI, myometrial invasion, and lymph node dissection (LND) was significantly different in the two groups.

\section{Univariate Analyses Between LNM and Clinicopathologic Features}

As determined by univariate analysis, ionized calcium (OR=11.9, 95\% CI: 4.8-29.6, $P<0.001)$, CA125 level (OR=1.05, 95\% CI: $1.01-1.13, P=0.001)$, tumor grade (OR=54.6, 95\% CI: 7.3-408.1, $P<0.001$ ), peritoneal cytology $(\mathrm{OR}=3.6,95 \% \mathrm{CI}: 1.6-8.2, P=0.003)$, FIGO stage $(\mathrm{OR}=199.7,95 \% \mathrm{CI}: 21.6-2083.9, P<0.001)$, histological type $(\mathrm{OR}=6.0,95 \%$ CI: 3.1-11.6, $P<0.001)$, LVSI $\quad(\mathrm{OR}=8.9, \quad 95 \% \quad \mathrm{CI}: \quad 4.6-16.9$,
$P<0.001)$, and myometrial invasion $(\mathrm{OR}=1.4,95 \%$ CI: $1.3-1.6, P<0.001)$ were all significantly associated with LNM whereas age, BMI, calcium level, menopausal state, diabetes, and hypertension were not $(P>0.05)$. The risk of LNM increased with the elevation of ionized calcium level ( $P$ for trend $<0.001$, Table 2 ).

\section{Relationship Between lonized Calcium Level and LNM}

To investigate the relationship between calcium level and LNM, we conducted multivariate analysis. We built different models by adjusting different confounding factors. Model I adjusted for the baseline information of patients and Model II added in all significantly risk factors in univariate analysis including CA125, tumor grade, myometrial invasion, and histological type. The results were shown in Table 3. There was no significant association between total serum level and LNM whether adjusting confounding factors or not $(\mathrm{OR}=0.5,95 \%$ $\mathrm{CI}=0.1-3.1)$. We further conducted multivariate analysis for the relationship between ionized calcium level and LNM. We saw significant positive associations between increasing ionized calcium level and LNM in unadjusted model (OR = $11.9,95 \% \mathrm{CI}=4.8-29.6, P<0.01)$, model $\mathrm{I}(\mathrm{OR}=11.3,95 \% \mathrm{CI}$ $=4.5-28.8, P<0.01)$ and model II $(\mathrm{OR}=5.2,95 \% \mathrm{CI}=1.6-$ 17.2, $P<0.05)$. The elevation of ionized calcium level was also significant in the multivariate model ( $P$ for trend $<0.01$ in unadjusted model, model I, and $P$ for trend $=0.037$ in model II).

The associations between the ionized calcium level and LNM stratified by demographic characteristics are shown in Figure 2. In most of the groups, high level of ionized calcium was positively correlated with LNM. The statistically significant associations were observed in these subgroups such as patients older than 60 years old (OR=10.51, 95\% CI: 1.25-42.59, $P<0.05)$, BMI < $28 \quad(\mathrm{OR}=9.39, \quad 95 \% \quad \mathrm{CI}: \quad 1.93-45.70, \quad P<0.01 \quad$ in $\mathrm{BMI}<24 \mathrm{~kg} / \mathrm{m}^{2}$ group; OR $=4.80,95 \%$ CI: $1.48-15.53$, $P<0.01$ in $\mathrm{BMI}=24-28 \mathrm{~kg} / \mathrm{m}^{2}$ group), grade 3 patients (OR=6.35, 95\% CI: 1.67-24.20, $P<0.01$ ), negative peritoneal cytology group $(\mathrm{OR}=2.92,95 \% \mathrm{CI}: 1.29-$ 6.64, $P<0.01)$ and EEA group $(\mathrm{OR}=6.90,95 \% \mathrm{CI}$ : 1 .$09-43.66, P<0.05)$ only. Interaction analysis revealed that all the factors had no impact on the association between the ionized calcium level and LNM which indicated that the relationship between ionized calcium level and LNM was stable in different groups (all $P$ for interaction $>0.05$ ). 
Table I Patient Characteristics

\begin{tabular}{|c|c|c|c|}
\hline Variables & Negative LNM Mean \pm SD or N (\%) & Positive LNM Mean \pm SD or $N(\%)$ & $P$ \\
\hline Total number & 401 & 47 & \\
\hline Age (years) & $55.5 \pm 9.5$ & $57.3 \pm 8.5$ & 0.182 \\
\hline BMI $\left(\mathrm{kg} / \mathrm{m}^{2}\right)$ & $26.5 \pm 4.7$ & $26.3 \pm 3.9$ & 0.955 \\
\hline Serum calcium (mg/dL) & $2.3 \pm 0.2$ & $2.3 \pm 0.3$ & 0.219 \\
\hline Serum albumin $(g / L)$ & $4.4 \pm 0.4$ & $4.0 \pm 0.5$ & $<0.001$ \\
\hline lonized calcium (mg/dL) & $2.0 \pm 0.3$ & $2.3 \pm 0.5$ & $<0.001$ \\
\hline CAI25 (U/mL) & $39.7 \pm 98.5$ & $172.8 \pm 459.5$ & $<0.001$ \\
\hline Number of $\mathrm{LN}$ removed & $16.5 \pm 10.8$ & $18.9 \pm 8.2$ & 0.168 \\
\hline $\begin{array}{l}\text { Postmenopausal status } \\
\text { No } \\
\text { Yes }\end{array}$ & $\begin{array}{l}143(35.7) \\
258(64.3)\end{array}$ & $\begin{array}{l}20(42.6) \\
27(57.4)\end{array}$ & 0.353 \\
\hline $\begin{array}{l}\text { Diabetes } \\
\text { No } \\
\text { Yes }\end{array}$ & $\begin{array}{l}310(77.3) \\
91(22.7)\end{array}$ & $\begin{array}{l}37(78.7) \\
10(21.3)\end{array}$ & 0.826 \\
\hline $\begin{array}{l}\text { Hypertension } \\
\text { No } \\
\text { Yes }\end{array}$ & $\begin{array}{l}237(59.1) \\
164(40.9)\end{array}$ & $\begin{array}{l}24(51.1) \\
23(48.9)\end{array}$ & 0.290 \\
\hline $\begin{array}{l}\text { Tumor grade } \\
\text { GI/G2 } \\
\text { G3 }\end{array}$ & $\begin{array}{l}323(80.5) \\
78(19.5)\end{array}$ & $\begin{array}{l}17(36.2) \\
30(63.8)\end{array}$ & $<0.001$ \\
\hline $\begin{array}{l}\text { Peritoneal cytology } \\
\text { Negative } \\
\text { Positive }\end{array}$ & $\begin{array}{l}376(93.8) \\
25(6.2)\end{array}$ & $\begin{array}{l}38(80.9) \\
9(19.1)\end{array}$ & 0.005 \\
\hline $\begin{array}{l}2009 \text { FIGO } \\
\text { I } \\
\text { II-IV }\end{array}$ & $\begin{array}{l}349(87.0) \\
52(13.0)\end{array}$ & $\begin{array}{l}0(0.0) \\
47(100.0)\end{array}$ & $<0.001$ \\
\hline $\begin{array}{l}\text { Histological type } \\
\text { EEA } \\
\text { Other types }\end{array}$ & $\begin{array}{l}357(89.0) \\
44(I I .0)\end{array}$ & $\begin{array}{l}27(57.4) \\
20(42.6)\end{array}$ & $<0.001$ \\
\hline $\begin{array}{l}\text { LVSI } \\
\text { Negative } \\
\text { Positive }\end{array}$ & $\begin{array}{l}348(86.8) \\
53(13.2)\end{array}$ & $\begin{array}{l}20(42.6) \\
27(57.4)\end{array}$ & $<0.001$ \\
\hline $\begin{array}{l}\text { Myometrial invasion } \\
<50 \% \\
\geq 50 \%\end{array}$ & $\begin{array}{l}292(72.8) \\
109(27.2)\end{array}$ & $\begin{array}{l}0(0.0) \\
47(100.0)\end{array}$ & $<0.001$ \\
\hline $\begin{array}{l}\text { Lymphadenectomy } \\
\text { No } \\
\text { Yes }\end{array}$ & $\begin{array}{l}76(18.9) \\
326(81.1)\end{array}$ & $\begin{array}{l}0(0.0) \\
46(100.0)\end{array}$ & $<0.001$ \\
\hline
\end{tabular}

Abbreviations: N, number; LNM, lymph node metastasis; LN, lymph node; BMI, body mass index; SD, standard deviation; G, tumor grade; FIGO, International Federation of Gynecology and Obstetrics; EEA, endometrioid endometrial adenocarcinoma; LVSI, lymph-vascular space invasion. 
Table 2 Results of Univariate Logistic Regression Analysis in EC Patients

\begin{tabular}{|c|c|c|}
\hline \multirow[t]{2}{*}{ Variables } & \multicolumn{2}{|l|}{ Univariate Analysis } \\
\hline & OR (95\% Cl) & $P$ \\
\hline Age & $1.0(1.0,1.1)$ & 0.225 \\
\hline BMI & $1.0(0.9,1.1)$ & 0.796 \\
\hline Serum calcium & I.I $(0.2,5.9)$ & 0.884 \\
\hline Serum albumin & $0.2(0.1,0.4)$ & $<0.001$ \\
\hline lonized calcium & $11.9(4.8,29.6)$ & $<0.001$ \\
\hline CAI25 & $1.05(1.01,1.13)$ & 0.001 \\
\hline Menopausal status & $0.7(0.4,1.4)$ & 0.354 \\
\hline Diabetes & $0.9(0.4,1.9)$ & 0.826 \\
\hline Hypertension & I.4 $(0.8,2.5)$ & 0.292 \\
\hline Tumor grade & $54.6(7.3,408.1)$ & $<0.001$ \\
\hline Peritoneal cytology & $3.6(1.6,8.2)$ & 0.003 \\
\hline FIGO stage & 199.7 (21.6, 2083.9) & $<0.001$ \\
\hline Histological type & $6.0(3.1,11.6)$ & $<0.001$ \\
\hline LVSI & $8.9(4.6,16.9)$ & $<0.001$ \\
\hline Myometrial invasion & I.4 (I.3, I.6) & $<0.001$ \\
\hline lonized calcium & & $P$ for trend \\
\hline Low $(0.56-1.85 \mathrm{mg} / \mathrm{dL})$ & 1.0 & \\
\hline Medium (I.85-2.07mg/dL) & $1.0(0.3,2.9)$ & \\
\hline High $(2.07-3.38 \mathrm{mg} / \mathrm{dL})$ & $5.5(2.3,12.9)$ & $<0.001$ \\
\hline
\end{tabular}

Abbreviations: $\mathrm{BMI}$, body mass index; $\mathrm{OR}$, odds ratio; $\mathrm{Cl}$, confidence interval; FIGO, International Federation of Gynecology and Obstetrics; LVSI, lymph vascular space invasion.

\section{Discussion}

Lymph node metastasis (LNM) is an important prognostic factor for survival and recurrence and is also the most common site of extra-uterine metastasis in patients with EC. ${ }^{1}$ The discrimination of patients with positive LNM is essential for tailoring adjuvant therapy and prognosis, but the therapeutic value of routine lymphadenectomy still remains controversial. Although two prospective randomized trials ${ }^{10}$ and a Surveillance, Epidemiology and End Results (SEER) Program analysis ${ }^{11}$ have reported that systematic lymphadenectomy did not improve overall or disease-free survival in EC, there are still several studies suggesting that lymphadenectomy is beneficial for EC. ${ }^{12,13}$ Predictions of LNM are well studied in EC patients, especially in FIGO stage I. One recent study constructed a nomogram for predicting the overall survival and found the nomogram was more accurate than the Mayo criteria. ${ }^{14}$ Other studies focused on a risk matrix model to identify high-risk parameters necessitating lymphadenectomy and to decide the risks and benefits of lymphadenectomy. ${ }^{15}$ A long-term argument against routine lymph node dissection was that the procedure could cause several complications such as bowel obstruction, deep venous thrombus and chronic lymphedema. ${ }^{16}$

To decrease complications related with lymphadenectomy and better select patients who would benefit most from lymphadenectomy, sentinel lymph node biopsy has been developed. Our institution has increasingly used sentinel lymph node evaluation, which involves injection of dye into the cervix and the dye travels to the sentinel nodes. The overall detection rate of sentinel lymph node in our department was $95 \%$, with $74 \%$ positive bilaterally. ${ }^{17}$ In addition, identification of risk factors is also an important measurement for conducting lymphadenectomy.

In our study, we tried to discern biomarkers for LNM before surgery to aid in prognosis and adjuvant treatment decisions. We found that ionized calcium, CA125 level, tumor grade, peritoneal cytology, FIGO stage, histological type, LVSI, and myometrial invasion were all significantly correlated with LNM. Further in the multivariate analysis, serum ionized calcium remained to be independent

Table 3 Logistic Regression Models Evaluating the Relationship Between LNM with Serum lonized Calcium

\begin{tabular}{|c|c|c|c|}
\hline Variables & Unadjusted OR (95\% Cl) & Model I I OR (95\% Cl) & Model II' OR (95\% Cl) \\
\hline Serum calcium level & I.I $(0.2,5.9)$ & I.I $(0.2,5.8)$ & $0.5(0.1,3.1)$ \\
\hline lonized calcium level & $11.9(4.8,29.6)^{* *}$ & $11.3(4.5,28.8)^{* *}$ & $5.2(1.6,17.2)^{*}$ \\
\hline Low & 1.0 & 1.0 & 1.0 \\
\hline Medium & $1.0(0.3,2.9)$ & $0.9(0.3,2.7)$ & $0.7(0.2,2.5)$ \\
\hline High & $5.6(2.4,13.2)$ & $5.3(2.2,12.5)$ & $2.9(I . I, 8 . I)$ \\
\hline$P$ for trend & $<0.01$ & $<0.01$ & 0.037 \\
\hline
\end{tabular}

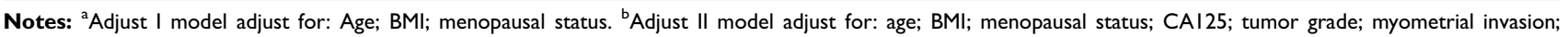
histological type; $* P<0.05$, $* * P<0.01$.

Abbreviations: LNM, lymph node metastasis; OR, odds ratio; $\mathrm{Cl}$, confidence interval. 


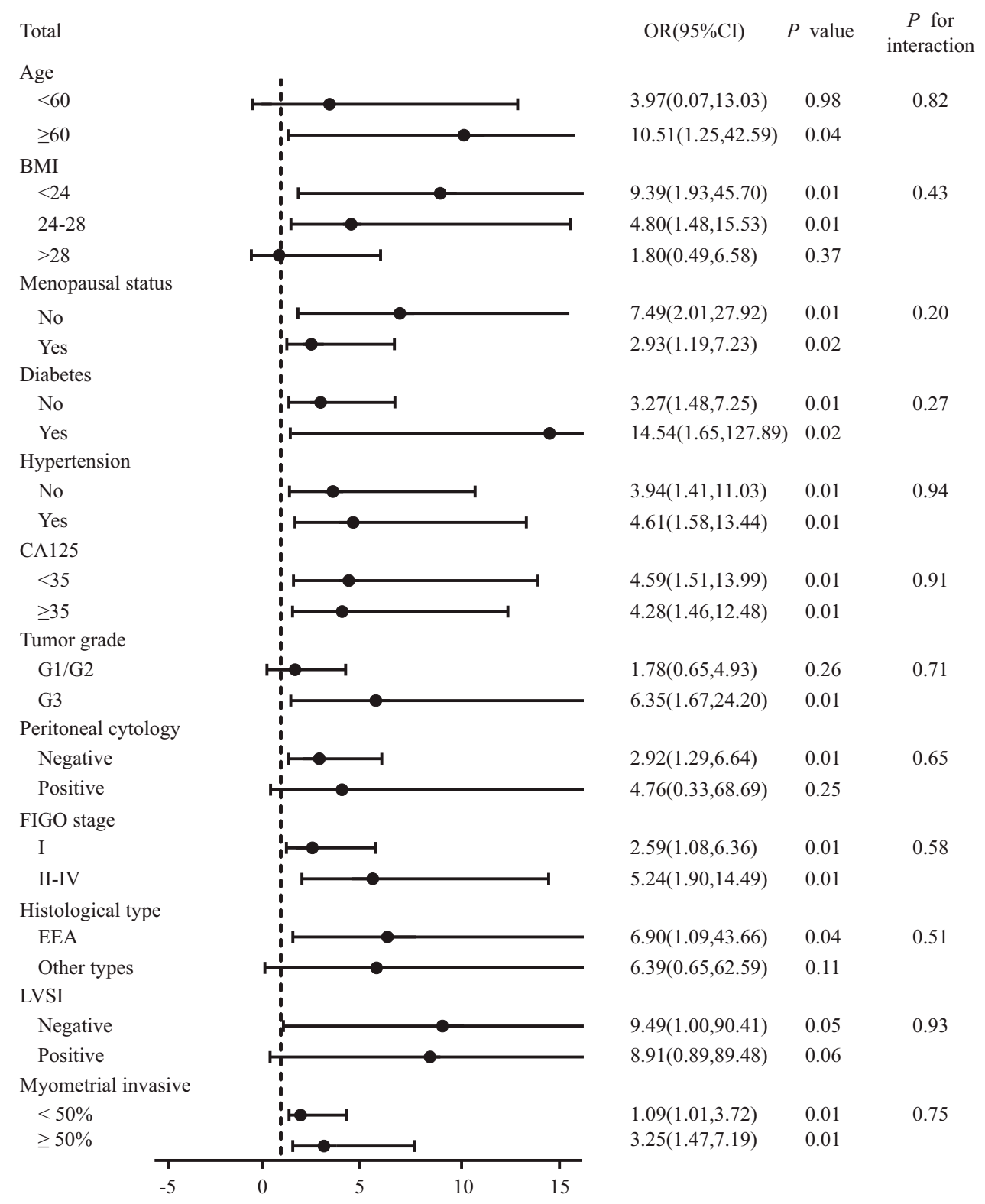

Figure 2 Stratification analysis of association between serum ionized calcium level and lymph node metastasis.

Abbreviations: BMI, body mass index; OR, odds ratio; Cl, confidence interval; G, tumor grade; FIGO, International Federation of Gynecology and Obstetrics; EEA, endometrioid endometrial adenocarcinoma; LVSI, lymph-vascular space invasion.

pathologic predictor of LNM before and after the adjustment of preoperative cofounders, suggesting that serumionized calcium might contribute to the metastatic ability of EC cells. What's more, our study revealed that the increased level of ionized calcium was positively associated with the risk of LNM in EC patients excluding other clinicopathological features that may affect the development of EC. By grouping the ionized calcium level into three levels, we found that the positive relationship between serum-ionized calcium and LNM was doseresponsible ( $P$ for trend $<0.01)$.
Previously in our study, we demonstrated that in EC patients, serum calcium might be a more sensitive parameter for metabolic syndrome, which is a well-established risk factor for EC. ${ }^{18}$ Another formation of metastatic tumor cells, positive peritoneal cytology, had a strong correlation with elevated ionized calcium level, indicating that calcium might have an effect on metastatic ability of EC cells. ${ }^{19}$ It was reported that up-regulated calcium level might lead to the metabolic syndrome through $\mathrm{Ca}^{2+} / \mathrm{cAMP}$ signaling pathway. ${ }^{20}$ What's more, epidemiological and clinical studies had found that metabolic syndrome was associated with the 
incidence of EC. ${ }^{21}$ Therefore, the underlying mechanism that calcium elevation in patients with LNM might be associated with metabolic syndrome in EC. There were studies concentrated on calcium level or ionized calcium in other cancers. For example, serum calcium was a risk factor for bone metastases in bladder cancer, ${ }^{22}$ and it was also associated with mammographic density in breast cancer. ${ }^{23}$ Kelly et al built a model using serum calcium and albumin to distinguish malignant and benign pelvic masses. ${ }^{24}$ These studies provided us with new insight into the potential mechanism, but they did not consider the influence of calcium level categories on the risk of the diseases and found the special group by stratification analysis.

The mechanism for the metastatic ability of $\mathrm{Ca}^{2+}$ on LNM was still ongoing. Calcium ion $\left(\mathrm{Ca}^{2+}\right)$ acted as a predictive role in many cancers, such as prostate, ovarian, and breast cancers. ${ }^{25} \mathrm{Ca}^{2+}$ and its related channels were found to promote cell migration not only in EC, but also in hepatocellular carcinoma, ${ }^{26}$ indicating that cancer cells might require a higher $\mathrm{Ca}^{2+}$ microenvironment and more active $\mathrm{Ca}^{2+}$ uptake. Estrogen was also an essential factor for the development of $\mathrm{EC},{ }^{27}$ and previous studies from our group had found that estrogen might work synergistically with calcium. ${ }^{7}$ The association between higher serum calcium and different cancers had long been reported. Total and ionized serum calcium could elevate the risk for fatal prostate cancer, ${ }^{22}$ acted as a risk factor for bone metastasis in bladder cancer ${ }^{24}$ and discriminated malignant pelvic masses from benign. ${ }^{28}$ All these results agreed with our observations that elevated ionized calcium levels were a negative prognostic factor for LNM in EC patients. Possibly, hyperactive calcium channels might promote metastatic dissemination and colonization by reorganizing the actin cytoskeleton, degrading the extracellular matrix and remodeling the tumor microenvironment. ${ }^{29}$

To the best of our knowledge, this is the first study to investigate the relationship between serumionized calcium level and the LNM in EC. Although the results of this study are interesting and compelling, there are still some limitations that need to be addressed. First, this is a retrospective study and some of the patients' records are missing, which leads to patient selection bias. Second, the study is conducted in a single medical center with a relatively small sample, which may not represent the generalized characteristics of the whole EC population. The third limitation is that our model has not been validated by other groups. In the future, we plan to carry out a validation study in other centers and explore the mechanism of metastatic lymph node cells caused by calcium levels.

\section{Conclusions}

We have shown that serum ionized calcium was independent risk factors for LNM in EC patients. The risk of LNM in EC increased with the ascending of ionized calcium levels. We also found the association was more obvious in patients whose age was older than $60, \mathrm{BMI}<28 \mathrm{~kg} / \mathrm{m}^{2}$, G3, negative peritoneal cytology, and EEA. The exact mechanism of action of calcium in metastasis called for deeper research and our findings needed to be confirmed by additional well designed randomized controlled studies.

\section{Ethical Approval}

The study was approved by Ethics Committee of the Peking University People's Hospital.

\section{Acknowledgments}

We especially appreciate Jiayang Jin, $\mathrm{PhD}$ of Peking University People's Hospital Rheumatology Department for study design consultations and editing the manuscript. This study was funded by the grants from the National Key Technology R\&D Program of China (Grant Nos 2019YFC1005200 and 2019YFC1005201) and National Natural Science Foundation of China (Grant No 81874108 and 81802607).

\section{Author Contributions}

All authors made substantial contributions to conception and design, acquisition of data, or analysis and interpretation of data; took part in drafting the article or revising it critically for important intellectual content; gave final approval of the version to be published; and agree to be accountable for all aspects of the work.

\section{Disclosure}

The authors report no conflicts of interest in this work.

\section{References}

1. Morice P, Leary A, Creutzberg C, Abu-Rustum N, Darai E. Endometrial cancer. Lancet. 2016;387(10023):1094-1108. doi:10.1016/S0140-6736(15)00130-0

2. Miller KD, Siegel RL, Lin CC, et al. Cancer treatment and survivorship statistics, 2016. CA Cancer J Clin. 2016;66(4):271-289. doi:10.3322/caac. 21349

3. Group A, Kitchener H, Swart AM, Qian Q, Amos C, Parmar MK. Efficacy of systematic pelvic lymphadenectomy in endometrial cancer (MRC ASTEC trial): a randomised study. Lancet. 2009;373 (9658):125-136. doi:10.1016/S0140-6736(08)61766-3

4. Mariani A, Webb MJ, Keeney GL, Haddock MG, Calori G, Podratz KC. Low-risk corpus cancer: is lymphadenectomy or radiotherapy necessary? Am J Obstet Gynecol. 2000;182(6):1506-1519. doi:10.1067/mob.2000.107335 
5. Kang S, Kang WD, Chung HH, et al. Preoperative identification of a low-risk group for lymph node metastasis in endometrial cancer: a Korean gynecologic oncology group study. J Clin Oncol. 2012;30 (12):1329-1334. doi:10.1200/JCO.2011.38.2416

6. Almquist M, Anagnostaki L, Bondeson L, et al. Serum calcium and tumour aggressiveness in breast cancer: a prospective study of 7847 women. Eur J Cancer Prev. 2009;18(5):354-360. doi:10.1097/ CEJ.0b013e32832c386f

7. Hao J, Bao X, Jin $\mathrm{B}$, et al. $\mathrm{Ca}^{2+}$ channel subunit alpha $1 \mathrm{D}$ promotes proliferation and migration of endometrial cancer cells mediated by 17 beta-estradiol via the $\mathrm{G}$ protein-coupled estrogen receptor. FASEB J. 2015;29(7):2883-2893. doi:10.1096/fj.14-265603

8. Xie R, Xu J, Xiao Y, et al. Calcium promotes human gastric cancer via a novel coupling of calcium-sensing receptor and TRPV4 channel. Cancer Res. 2017;77(23):6499-6512. doi:10.1158/00085472.CAN-17-0360

9. Litta P, Fracas M, Pozzan C, et al. Laparoscopic management of early stage endometrial cancer. Eur J Gynaecol Oncol. 2003;24(1):41-44.

10. Benedetti Panici P, Basile S, Maneschi F, et al. Systematic pelvic lymphadenectomy vs. no lymphadenectomy in early-stage endometrial carcinoma: randomized clinical trial. J Natl Cancer Inst. 2008;100(23):1707-1716. doi:10.1093/jnci/djn397

11. Todo Y, Kato H, Kaneuchi M, Watari H, Takeda M, Sakuragi N. Survival effect of para-aortic lymphadenectomy in endometrial cancer (SEPAL study): a retrospective cohort analysis. Lancet. 2010;375 (9721):1165-1172. doi:10.1016/S0140-6736(09)62002-X

12. Eggemann H, Ignatov T, Kaiser K, Burger E, Costa SD, Ignatov A. Survival advantage of lymphadenectomy in endometrial cancer. $J$ Cancer Res Clin Oncol. 2016;142(5):1051-1060. doi:10.1007/ s00432-015-2109-9

13. Cragun JM, Havrilesky LJ, Calingaert B, et al. Retrospective analysis of selective lymphadenectomy in apparent early-stage endometrial cancer. J Clin Oncol. 2005;23(16):3668-3675. doi:10.1200/ JCO.2005.04.144

14. Dong Y, Cheng Y, Tian W, et al. An externally validated nomogram for predicting lymph node metastasis of presumed stage I and II endometrial cancer. Front Oncol. 2019;9:1218. doi:10.3389/ fonc. 2019.01218

15. Anton C, Baracat EC, Dogan NU, Kohler C, Carvalho JP, Di Favero GM. A novel model to estimate lymph node metastasis in endometrial cancer patients. Clinics. 2017;72(1):30-35. doi:10.6061/ clinics/2017(01)06

16. Liang SC, Wang ZQ, Wang JL. [Clinical analysis of 76 cases of sentinel lymph node detection in cervical cancer and endometrial cancer]. Zhonghua Fu Chan Ke Za Zhi. 2017;52(9):605-611. doi:10.3760/cma.j.issn.0529-567X.2017.09.006. Chinese.
17. Chen S, Wang L, Qian K, et al. Establishing a prediction model for prostate cancer bone metastasis. Int J Biol Sci. 2019;15(1):208-220. doi:10.7150/ijbs. 27537

18. Lin Y, Zhou J, Cao L, et al. Serum calcium is a novel parameter to assess metabolic syndrome in endometrial carcinoma. J Gynecol Oncol. 2019;30(1):e12. doi:10.3802/jgo.2019.30.e12

19. Li X, Cheng Y, Dong Y, et al. An elevated preoperative serum calcium level is a significant predictor for positive peritoneal cytology in endometrial carcinoma. Chin J Cancer Res. 2019;31 (6):965-973. doi:10.21147/j.issn.1000-9604.2019.06.12

20. Bergantin LB. Diabetes and cancer: debating the link through $\mathrm{Ca}(2$ + )/cAMP signalling. Cancer Lett. 2019;448:128-131. doi:10.1016/j. canlet.2019.02.017

21. Yang $X$, Wang J. The role of metabolic syndrome in endometrial cancer: a review. Front Oncol. 2019;9:744. doi:10.3389/ fonc. 2019.00744

22. Huang P, Lan M, Peng AF, et al. Serum calcium, alkaline phosphatase and hemoglobin as risk factors for bone metastases in bladder cancer. PLoS One. 2017;12(9):e0183835. doi:10.1371/journal. pone. 0183835

23. Hack CC, Stoll MJ, Jud SM, et al. Correlation of mammographic density and serum calcium levels in patients with primary breast cancer. Cancer Med. 2017;6(6):1473-1481. doi:10.1002/cam4.1066

24. Kelly MG, Winkler SS, Lentz SS, et al. Serum calcium and serum albumin are biomarkers that can discriminate malignant from benign pelvic masses. Cancer Epidemiol Biomarkers Prev. 2015;24 (10):1593-1598. doi:10.1158/1055-9965.EPI-15-0443

25. Sana AB, Maryan WF, Manal M, Mamdouh M. Calcium channel alpha2delta1 subunit as a novel biomarker for diagnosis of hepatocellular carcinoma. Cancer Biol Med. 2018;15(1):52-60. doi:10.20892/j.issn.2095-3941.2017.0167

26. Wenyan T, Fei T, Jinping G, et al. Estrogen and insulin synergistically promote endometrial cancer progression via crosstalk between their receptor signaling pathways. Cancer Biol Med. 2019;16 (1):55-70. doi:10.20892/j.issn.2095-3941.2018.0157

27. Schwartz GG, Skinner HG. A prospective study of total and ionized serum calcium and time to fatal prostate cancer. Cancer Epidemiol Biomarkers Prev. 2012;21(10):1768-1773. doi:10.1158/1055-9965. EPI-12-0585

28. Mo P, Yang S. The store-operated calcium channels in cancer metastasis: from cell migration, invasion to metastatic colonization. Front Biosci. 2018;23:1241-1256. doi:10.2741/4641

29. Kang S, Nam JH, Bae DS, et al. Preoperative assessment of lymph node metastasis in endometrial cancer: a Korean Gynecologic Oncology Group study. Cancer. 2017;123(2):263-272. doi:10.1002/ cncr.30349

\section{Publish your work in this journal}

Cancer Management and Research is an international, peer-reviewed open access journal focusing on cancer research and the optimal use of preventative and integrated treatment interventions to achieve improved outcomes, enhanced survival and quality of life for the cancer patient.
The manuscript management system is completely online and includes a very quick and fair peer-review system, which is all easy to use. Visit http://www.dovepress.com/testimonials.php to read real quotes from published authors. 